\title{
Plexiform neurofibroma of the submandibular salivary gland in a child
}

\author{
Jacqueline M Bourgeois MD FRCPC ${ }^{1}$, Jasim Radhi MD FRCPUK FRCPC ${ }^{1}$, \\ Lisa Elden MD FRCSC ${ }^{2}$, Gerald Gill MD FRCPC ${ }^{3}$
}

\begin{abstract}
JM Bourgeois, J Radhi, L Elden, G Gill. Plexiform neurofibroma of the submandibular salivary gland in a child. Can J Gastroenterol 2001;15(12):835-837. Plexiform neurofibromas in major salivary glands are rarely described. In the literature, most reported tumours have been present in the parotid gland region. A three-year-old boy with a family history of neurofibromatosis presented with a rapidly growing left submandibular mass. The clinical diagnosis was that of a neurofibroma rather than a primary salivery gland tumour. Resection of the lesion revealed a plexiform neurofibroma involving the submandibular gland. Although these tumours have a neurogenic rather than a salivary gland origin, they must be considered in the differential diagnosis of a salivary gland lesion in a patient with a history of neurofibromatosis.
\end{abstract}

\section{Neurofibrome plexiforme de la glande salivaire sous-mandibulaire chez un enfant}

RÉSUMÉ : Le neurofibrome plexiforme est rarement décrit au niveau de la glande salivaire sous-mandibulaire. Dans la littérature, la plupart des tumeurs mentionnées se sont développées dans la région de la glande parotide. Chez un garçon de trois ans ayant des antécédants familiaux de neurofibromatose une masse sous-mandibulaire s'est rapidement développée. Le diagnostic clinique a été celui de neurofibrome plutôt que de tumeur primitive de la glande salivaire. La résection de la lésion a révélé un neurofibrome plexiforme de la glande sous-madibulaire. Bien que ces tumeurs aient une origine neurogène plutôt de provenir de la glande salivaire, il faut toujours les envisager dans le diagnostic différentiel d'une lésion de la glande salivaire chez un patient qui a des antécédents de neurofibromatose.

Key Words: Plexiform neurofibroma; Salivary glands

$\mathrm{N}$ eurofibromatosis type 1 is an autosomal dominant inherited neurocutaneous syndrome with an incidence of one per 3000 births (1). A mutation on chromosome 17 is responsible for Von Recklinghousen's disease (2). The clinical diagnosis is based on the criteria as outlined by the National Institutes of Health consensus conference (3). Patients present with multiple lesions, including café-au-lait spots, osseous lesions, Lisch nodules, gliomas and neurofibromas.

Plexiform neurofibromas are nonmetastasizing, locally aggressive, invasive tumours that cause cosmetic and func- tional deformities in the head and neck region. They are rarely located in major salivary glands, but when present are most commonly located in the parotid gland region and seldom located in the submandibular region (4).

\section{CASE PRESENTATION}

A three-year-old boy with a history of inherited neurofibromatosis type 1 presented with a $3 \times 4 \mathrm{~cm}$ left submandibular triangle cervical mass that had grown rapidly over the preceding six to 12 months. A pea-sized mass in the same

\footnotetext{
${ }^{1}$ Department of Pathology and Molecular Medicine, ${ }^{2}$ Surgery and ${ }^{3}$ Radiology, McMaster University Medical Centre, McMaster University, Hamilton, Ontario

Correspondence: Dr J Radhi, McMaster University, Department of Anatomic Pathology and Molecular Medicine, Room 2N24, Hamilton Health

Sciences Corporation, McMaster University Medical Center, 1200 Main Street West, Hamilton, Ontario L8N 325.

Telephone 905-521-2100 ext 76313,fax 905-577-0198, e-mail radhi@hhsc.ca

Received for publication September 17, 2001. Accepted October 15, 2001
} 


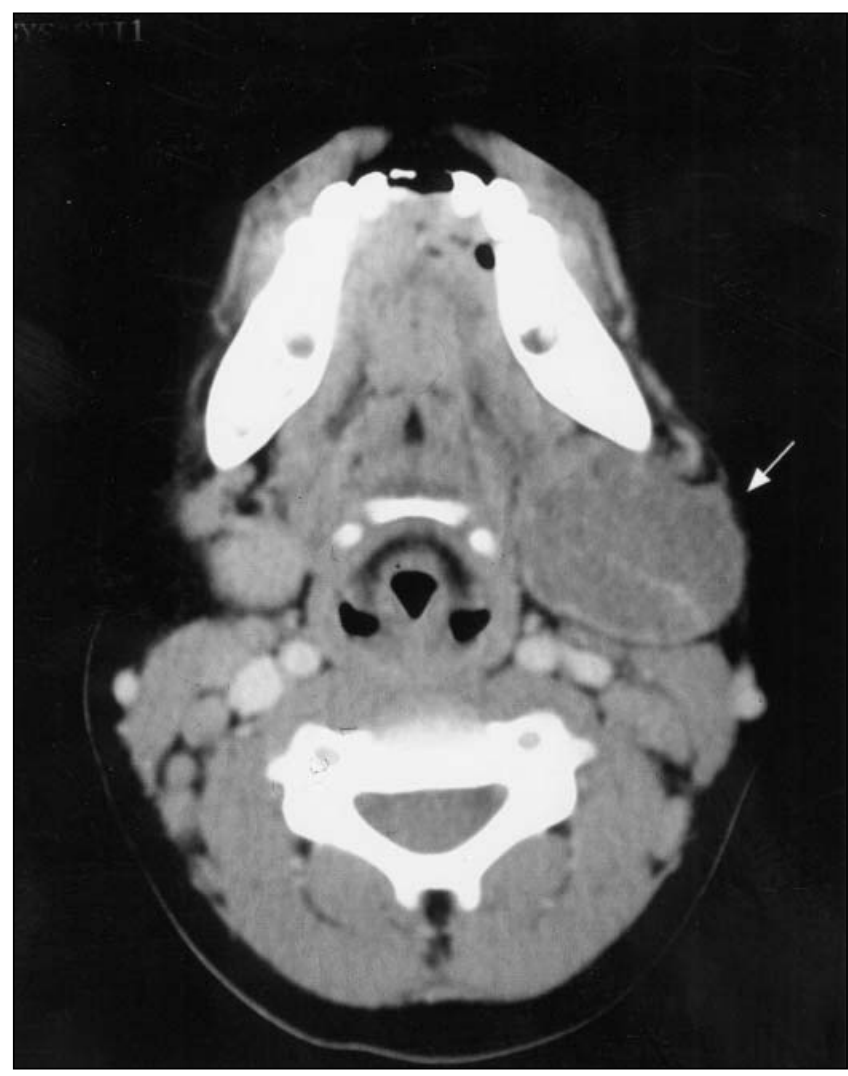

Figure 1) Computed tomography axial section with contrast enhancement showing a left submandibular gland mass (arrow) measuring $4.5 \mathrm{~cm}$ in maximum dimension and having a predominantly low soft tissue density with several higher density interconnecting strands

region had been present since infancy and had been aspirated when the patient was approximately one to one-anda-half years of age. His medical history included a tonsillectomy for an unrelated problem. The child was otherwise healthy, and the only manifestations of neurofibromatosis were the presence of multiple café au lait spots. Results of a neurological examination were normal.

A computed tomography scan was performed with and without intravenous contrast enhancement of the neck. A mass measuring about $4.5 \mathrm{~cm}$ in its maximum dimension was associated with the left submandibular gland. On contrast enhancement, the lesion was seen to have welldefined margins and was predominantly composed of low soft tissue density, within which there were several interconnecting strands of a higher density (Figure 1). In a patient with neurofibromatosis type 1 , neurofibroma would be the most likely cause of the mass. However, in the pediatric population, the salivary gland tumours that should be included in the differential diagnosis, in descending order of frequency, are capillary hemangiomas, pleomorphic adenomas, mucoepidermoid carcinoma, lymphangiomatous-type tumours and acinic cell carcinoma.

The patient later underwent surgical excision of the tumour. A $3 \times 4 \mathrm{~cm}$ mass was identified and excised from the left submandibular triangle of the neck. Intraoperatively,

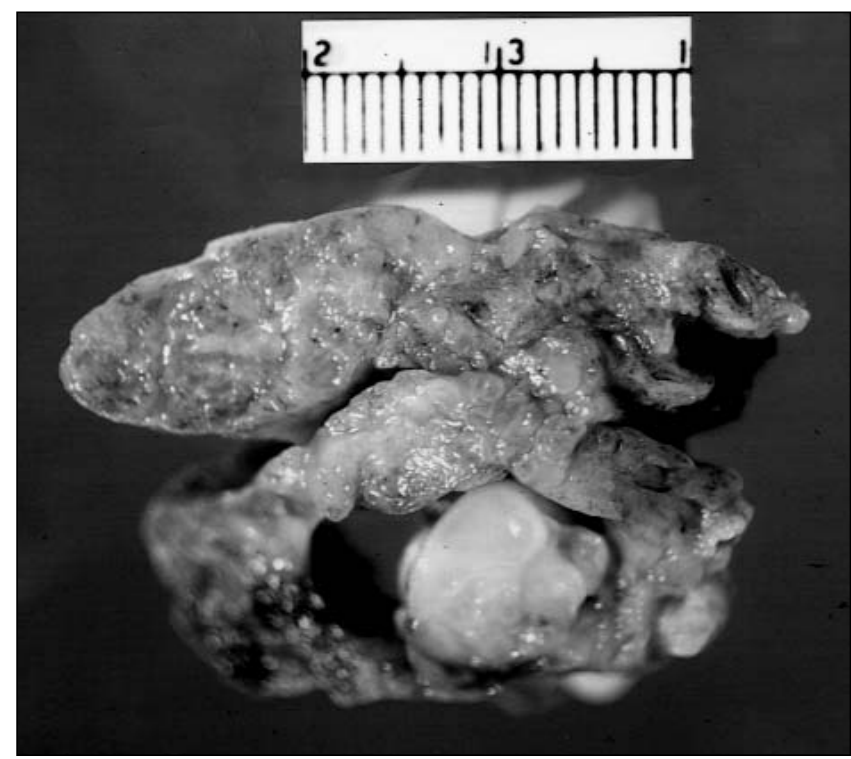

Figure 2) Gross cut surface appearance of the excised tumour. The tissue seen superiorly is residual salivary gland tissue. Note the myxoid appearance of the tumour centre

the lesion had a pale, tan, oval, glandular appearance, with a fleshy, oval, encapsulated mass attached laterally. The hypoglossal and laryngeal nerves were normal. The marginal mandibular nerve was not identified and showed some weakness postoperatively.

The initial aspirate for cytology that had been performed when the patient was approximately one to one-and-a-half years of age showed mixed lymphocytes and spindle cells that were suggestive, but not diagnostic, of neurofibroma. The surgical specimen consisted of a multilobulated, tan, spongy piece of soft tissue measuring $4.2 \times 4.0 \times 2.5 \mathrm{~cm}$. There was a portion of firm tubular tissue noted at one edge measuring $2.3 \mathrm{~cm}$ in length by $1.0 \mathrm{~cm}$ in maximum diameter. The cut surface showed a centrally located, well-demarcated, soft tan, slightly myxoid lesion (Figure 2).

Histologically, the sections were seen to be major salivary gland tissue that had been replaced and expanded by irregularly distorted, enlarged nerve bundles (Figure 3). The nerve bundles showed myxoid changes typical of a plexiform neurofibroma. The tubular structure noted grossly was a neurovascular bundle that was also involved with the neurofibroma (Figure 4).

\section{DISCUSSION}

Neurofibromas are benign tumours that consist of Schwann cells, nerve fibres and fibroblasts. The tumours are more commonly seen after puberty and less commonly in children. The plexiform type of neurofibromas are usually large, 'wormy' tumour masses that grow along nerves and extend into contagious tissue (5).

The present case of a plexiform neurofibroma identified in the submandibular salivary gland is a rare finding in a small child, even with the clinical diagnosis of neurofibromatosis type 1 . Most plexiform neurofibromas of the sali- 


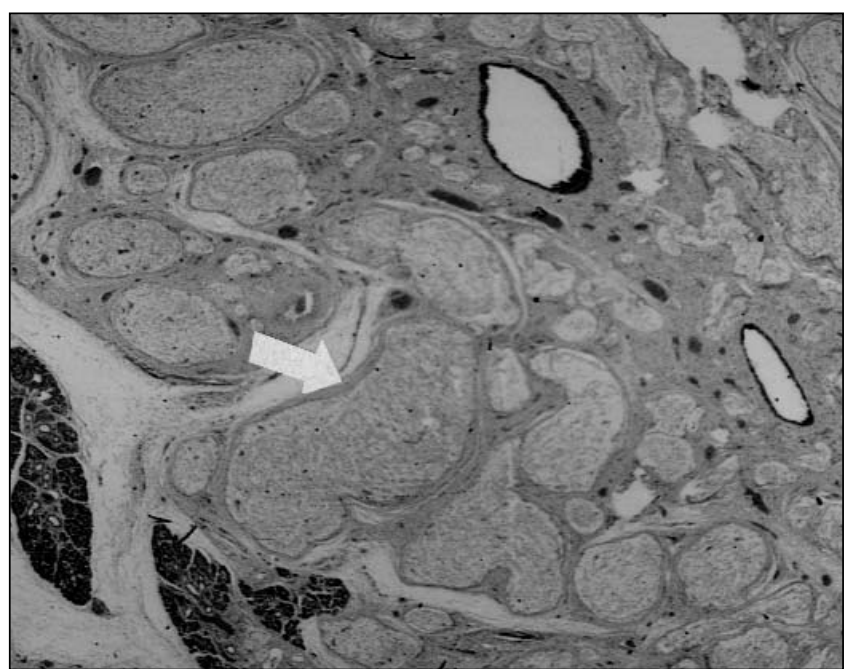

Figure 3) Histological appearance of the plexiform neurofibroma showing irregularly distorted and enlarged nerve bundles (arrow) with salivary gland tissue (hematoxylin and eosin stain, original magnification $\times 10$ )

vary gland that present in childhood are noted in the second decade of life and are more commonly located in the parotid gland (6). In the present case, a 'pea-sized' lesion had been present as an infant, with rapid growth in the six to 12 months preceding the excisional biopsy.

The present case highlights the necessity of follow-up, even in young patients with neurofibromatosis. Follow-up is even more important in those with lesions in the head and neck area. There have been reports of neurofibromas developing in this region that compromise the airway, causing death (7). In the present case, the surgical procedure was part of the definitive treatment, although a residual tumour was present at the resection margins (neurovascular bundle). Such a finding requires continued clinical follow-up, not only for airway considerations but also for malignant transformation, which is seen in $2 \%$ to $3 \%$ of cases (8).

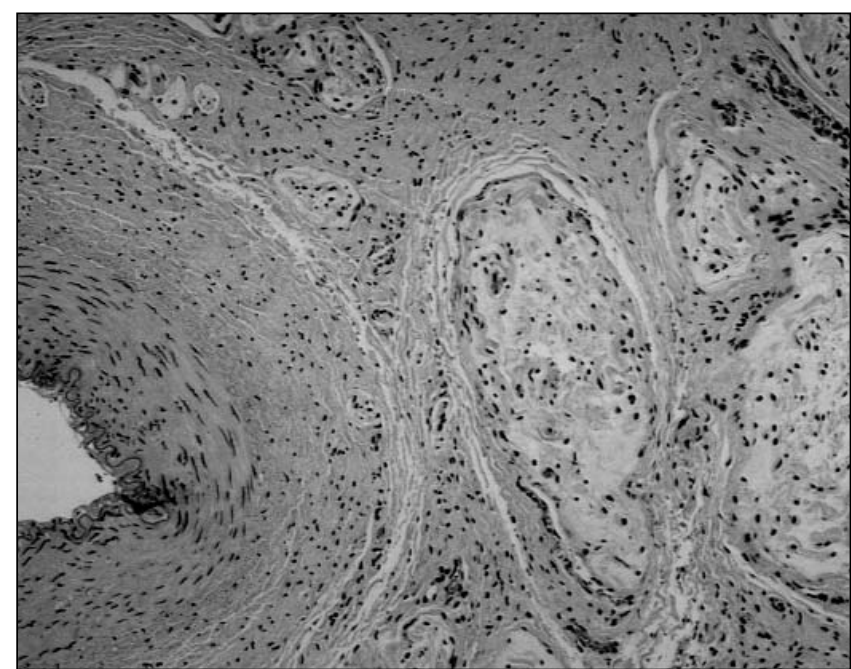

Figure 4) Histological appearance of the plexiform neurofibroma involving the neurovascular bundle (hematoxylin and eosin stain, original magnification $\times 10$ )

\section{REFERENCES}

1. Lazaro C, Ravella A, Gaona A, Bolpini V, Estivill X.

Neurofibromatosis type 1 due to germ-line mosaicism in a clinically normal father. N Engl J Med 1994;331:1403-7.

2. Barker D, Wright E, Nguyen L, et al. Gene for von Recklinghausen neurofibromatosis is in the pericentric region of chromosome 17. Science 1987;236:1100-2.

3. National Institutes of Health. Neurofibromatosis Consensus Development Conference Statement. Bethesda: National Institutes of Health, 1987.

4. Derekay S, Safali M. Plexiform neurofibroma of submandibular gland. J Laryngol Otol 2000;114:643-5.

5. Weitzner S. Plexiform neurofibroma of major salivary glands in children. Oral Surg 1980;50:53-7.

6. Blatt J, Jaffe R, Deutsch M, Adkins JC. Neurofibromatosis and childhood tumors. Cancer 1986;57:1225-9.

7. Yamada N, Uchinuma E, Shioya N, Shimamoto Y, Kuwao S, Fuktagami R. Plexiform neurofibromatosis in infant. Br J Plast Surg 1992;45:175-6.

8. Waggoner DJ, Towbin J, Gottesman G, Gutmann DH. Clinic-based study of plexiform neurofibromas in neurofibromatosis 1 . Am J Med Genet 2000;92:132-5. 


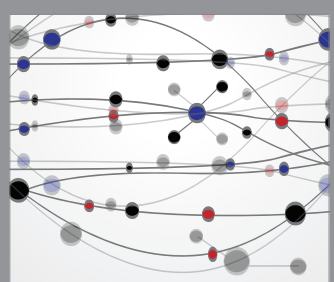

The Scientific World Journal
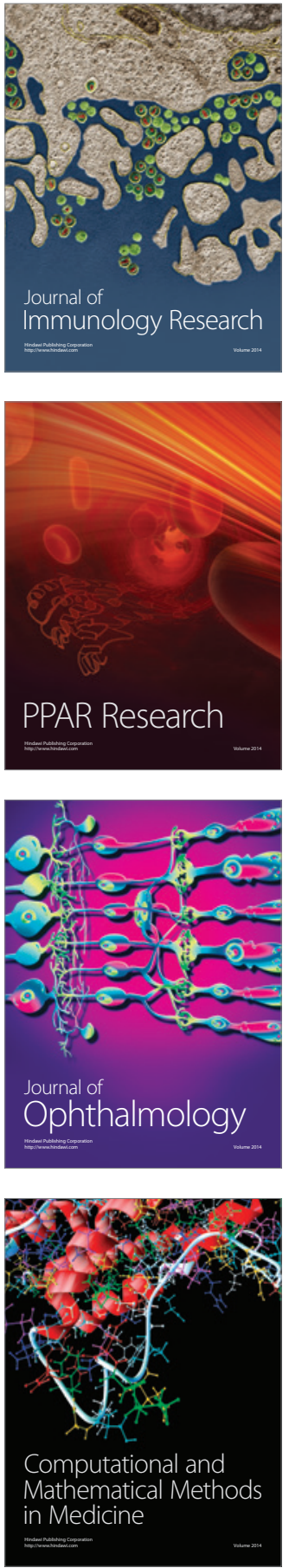

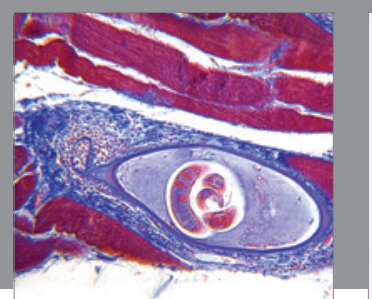

Gastroenterology Research and Practice

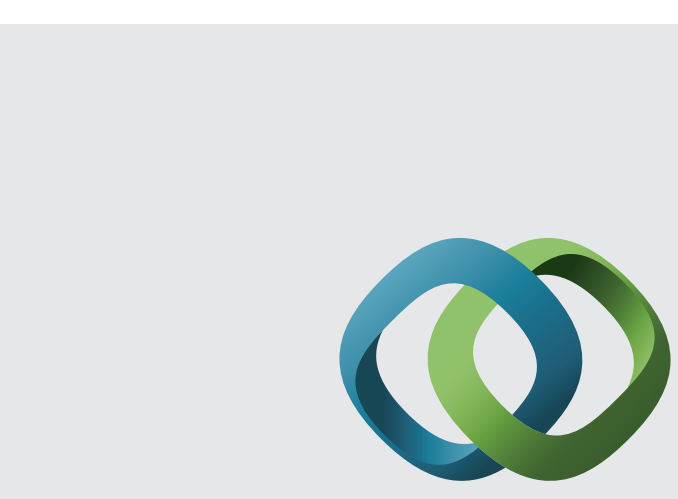

\section{Hindawi}

Submit your manuscripts at

http://www.hindawi.com
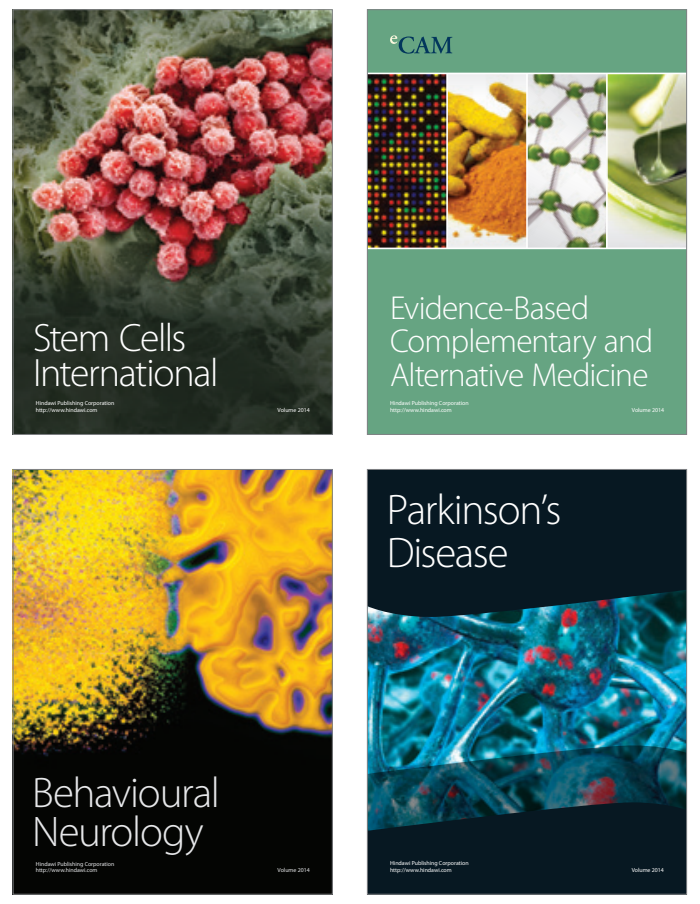
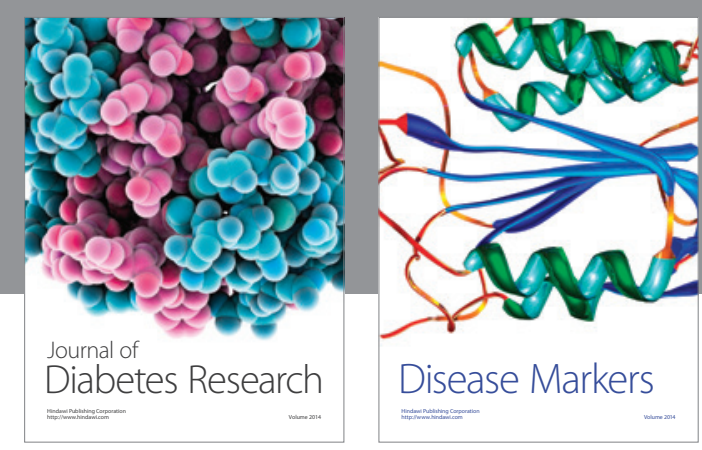

Disease Markers
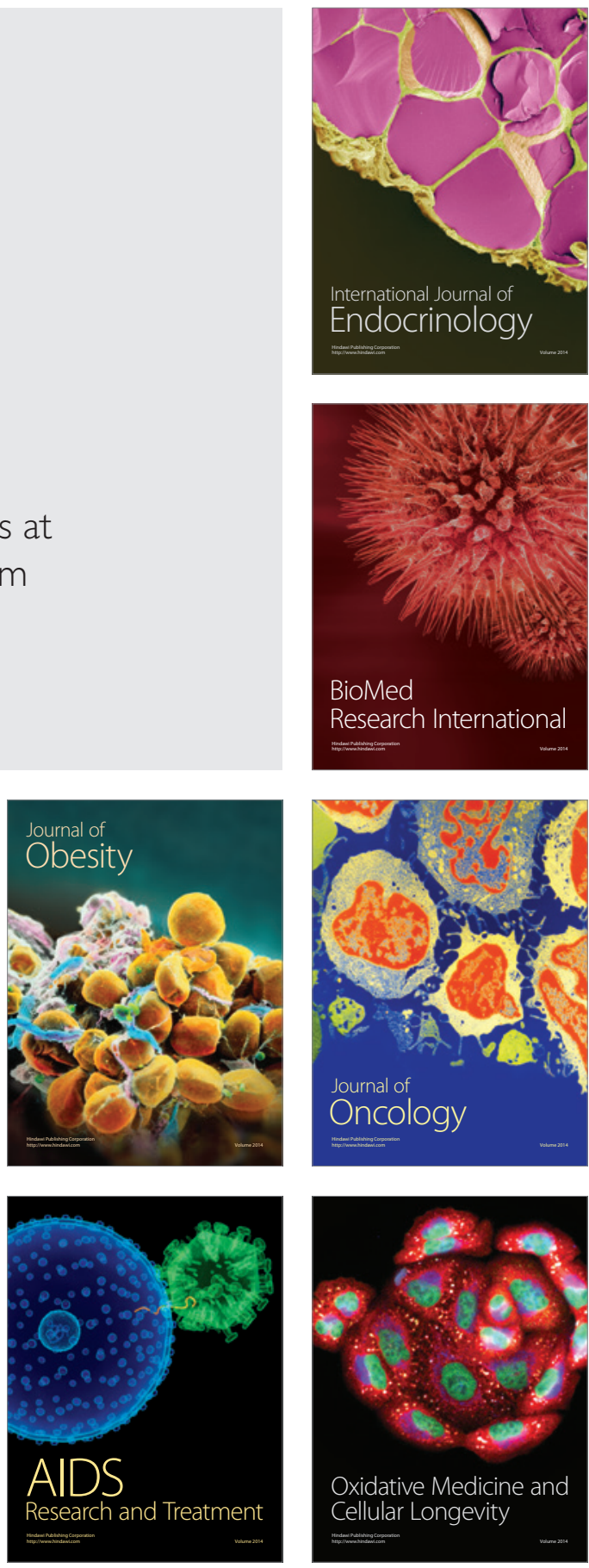